\title{
¿Una guerra de religión o una religión para la guerra? El elemento confesional en la Guerra de los Treinta Años ${ }^{\top}$

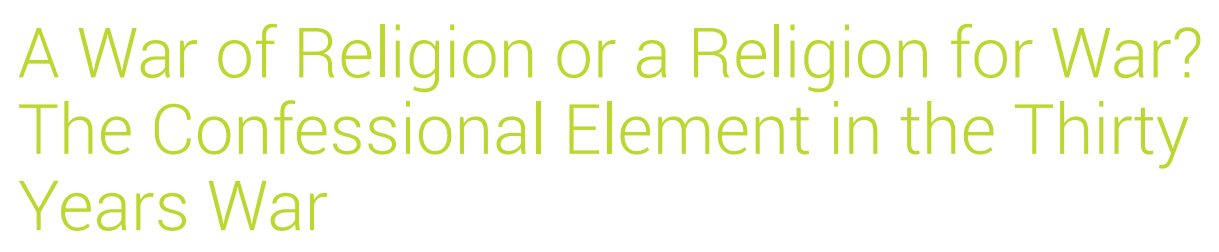

\section{Fernando Negredo del Cerro}

ORCID: https://orcid.org/0000-0001-6639-9649

Universidad Carlos III (Madrid)

ESPAÑA

fnegredo@hum.uc3m.es

[Hipogrifo, (issn: 2328-1308), 7.2, 2019, pp. 511-525]

Recibido: 16-04-2018/ Aceptado: 18-05-2018

DOI: http://dx.doi.org/10.13035/H.2019.07.02.40

Resumen. En el presente artículo pretendemos destacar cómo el hecho confesional no supuso, en realidad, la causa profunda de la guerra si no que, al contrario, fue el instrumento perfecto para proporcionar coberturas ideológicas y aglutinar voluntades en un mundo imbuido de un fuerte sentimiento religioso. En este sentido se recogen ejemplos precisos que debilitan la visión confesional de la guerra y se propone al final una explicación del porqué dicha interpretación ha tenido y tiene tanto predicamento en diferentes historiografías.

Palabras clave. Protestantismo; Catolicismo; confesionalización; revisión historiográfica.

1. Este texto forma parte del proyecto Del manuscrito a las pantallas: Memoria, artefactos y prácticas culturales (del siglo XV a nuestros días) financiado por el MElyC. Ref. HAR2016-76550P y recoge lo más sustancial de la ponencia presentada en el Congreso Internacional De la Reforma a la Guerra de los Treinta Años: literatura, historia, pensamiento y religión en el Siglo de Oro organizado por el Instituto de Estudios Hispánicos en la Modernidad de la Universitat de les Illes Balears en colaboración con el Grupo de Investigación Siglo de Oro (GRISO) de la Universidad de Navarra los días 8-9 de febrero de 2018. Agradezco a los asistentes al mismo las sugerencias hechas al respecto. Por cuestiones de espacio hemos acotado las notas a pie de página al mínimo imprescindible. 
Abstract. In this article, I intend to highlight how the confessional question was not, in fact, the underlying cause of the Thirty Years War. On the contrary, religion became the perfect instrument to provide ideological coverage for the conflict and to bring together different wills in a world imbued with a strong religious feeling. In this regard, precise examples are collected that weaken the confessional vision of war. Finally, we propose an explanation of why this interpretation has had (and still has) so much predicament among different historians and historiographical visions.

Keywords. Protestantism; Catholicism; Confessionalization; Historiographic review.

Plantear un interrogante como el que da título a este artículo podría, a primera vista, parecernos una cuestión baladí ya que desde casi su origen se ha considerado a la Guerra de los Treinta Años como el gran y último conflicto confesional'; y de hecho, en las propias paces de Westfalia que lo finiquitaron, allá por el mes de octubre de 1648, se afirmaba, en su capítulo 5, que «puesto que los asuntos de religión han sido en gran parte causa y ocasión de la presente guerra» era necesario solucionarlos ${ }^{3}$. Sin embargo, una lectura atenta de todo el proceso, fijándonos en los protagonistas, sus acciones y consecuencias, quizá nos permita una interpretación algo diferente de la hasta ahora comúnmente aceptada.

Ahora bien, una interpretación diferente no implica negar la importancia de la religión, de la que en ningún momento se podrá prescindir; antes más, lo que se pretende en las siguientes páginas es, una vez constatada su trascendencia, ubicarla en su justo término puesto que, y se antoja una obviedad recordarlo, en sociedades fuertemente sacralizadas y en donde el proceso de confesionalización se había ido implementando de forma tenaz y constante, el elemento religioso se manifiesta como fundamental para entenderlas ${ }^{4}$. No es que fuese una dimensión más del contexto vital de los habitantes europeos del siglo XVII, es que era el horizonte de creencias que daba sentido a la gran mayoría de las vidas de nuestros antepasados, de ahí que, como decimos, no se pueda ignorar. Pero precisamente por esto, acrisolar la dimensión confesional en la Guerra de los Treinta Años se revela como una cuestión nada superficial porque, de no hacerlo, corremos el riesgo de que los árboles no nos dejen ver el bosque.

Así las cosas, intentar dilucidar dicha cuestión -el peso real del elemento confesional sobre la toma de decisiones de los principales actores del drama- tiene, creo, una importancia mayor de la que en un rápido vistazo pudiera parecer pues, en realidad, el que demos una respuesta $u$ otra implica entender el conflicto en clave muy diferente y exige, en nuestro caso, repensar el porqué de la aceptación de una cierta tradición historiográfica como explicación monolítica del mismo. En

2. De forma implícita, varios libros con títulos referidos a elementos religiosos acaban en 1648. Ver Lutz, 2009 o Greengrass, 2015.

3. Abreu y Bertodano, Colección de los tratados de paz..., p. 503.

4. Sobre el proceso de confesionalización, idea esta nacida de la historiografía alemana y con gran predicamento tanto en Italia como España, Palomo, 2016. 
consonancia con ello, dudar de que la religión sea el motivo principal (y aun secundario) del enfrentamiento conlleva nuevas lecturas de todo un proceso que van más allá de la mera interpretación de la Guerra 5 .

En definitiva, lo que pretendemos es discernir si la religión fue la causa o, al menos, una de las razones que motivaron estos conflictos o, por el contrario, supuso el pretexto ideal para aunar voluntades y acallar críticas de tal manera que el esfuerzo bélico y las decisiones políticas a él vinculadas obtuvieran el respaldo de una sociedad a la que sería muy difícil motivar con otras explicaciones al respecto ${ }^{6}$. Y en este sentido y anticipando ya unas conclusiones que, creo, que tendremos ocasión de demostrar, me atrevo a afirmar que la religión operó, excepto en momentos muy concretos y puntuales, como un catalizador de voluntades sabiamente empleado por los poderes interesados en que así fuera?

En relación con lo que acabamos de decir, y al ser la religión la respuesta transcendente a las necesidades inmanentes, se nos presenta como el recurso perfecto para proporcionar la cobertura ideológica y justificativa más eficaz. Y así fue empleada, tanto por católicos como, sobre todo, por protestantes ya que fueron estos los grandes creadores de una publicística en donde se teñía de cuestión religiosa lo que, en la mayoría de las veces, no eran sino asuntos de poder y geoestrategia8; porque, como se ha puesto de manifiesto en innumerables casos, siempre fue mucho más sencillo mover a las masas apelando a discursos irracionales fuertemente ideologizados, léase, nacionalismo o religión, que no mediante explicaciones argumentadas. Al proporcionar un barniz confesional a lo que no eran sino disputas políticas se lograba una aceptación general y una irrebatibilidad que de otra forma se antojaba imposible de conseguir? .

5. Para interpretaciones muy diferentes de la Guerra de los Treinta Años ver tres trabajos ya clásicos y complementarios: Polisensky, 1974; Steinberg, 1966 y Wedgwood, 1938

6. Entendemos, por tanto, y a diferencia de Konrad Repgen, que una guerra de religión es aquella que tiene como elemento básico de confrontación y causa subyacente, el antagonismo confesional (aunque existan otras dimensiones en el conflicto). Este sería el caso de las «guerra de religión» francesas. Para este autor, por el contrario, basta con que «at least one of the belligerents lays claim to "religion", a religious law, in order to justify his warfare and to substantiate publicly why his use of military force against a political authority should be a bellum iustum» (Repgen, 1987, p. 313).

7. Un ejemplo altamente significativo: el mismísimo emperador Fernando II escribía a Wallenstein instándole a que empleara el «pretexto de la religión» (praetextum der Religion) en sus manifestaciones públicas, siguiendo así el ejemplo de sus enemigos. Ver Greegrass, 2015, p. 702. Sobre las complejas relaciones entre legalidad, necesidad y conciencia en el ámbito del gobierno francés durante la guerra, cfr. Sonnino, 2002. La importancia del elemento religioso, sin que esto anule el carácter de guerra político-dinástica, se plasma en las conclusiones a los trabajos reunidos en Forclaz y Martin, 2015, en especial p. 330

8. Para propaganda y noticias de época ofrece todavía interesantes aportaciones Rystad, 1960. Ver también el capítulo 23 de Wilson, 2009 y el capítulo III de Usunáriz, 2016.

9. Dos ejemplos nos sirven para ilustrar estas afirmaciones, por un lado la movilización que el bando imperial hizo antes, durante y después de la batalla de Montaña Blanca, leyéndola en clave mística (Chaline, 1999) y el recurso a los predicadores que la monarquía sueca empleó para legitimar su intervención en Alemania (Ringmar, 1996). 
Ahora bien, estas afirmaciones corren el peligro de quedarse en un mero discursos desiderativo si no se anclan en acontecimientos y comportamientos de época que los cimenten, de ahí que convenga exponer a continuación una serie de elementos (algunos muy conocidos, otros menos) que desde diferentes perspectivas, que intentaremos sean complementarias, nos permitan ponderar con cierta objetividad las diferentes respuestas a las preguntas que planteamos y dan título a este artículo.

Comencemos en el mismo año 1618. Los estados bohemios, rebelados en mayo contra su señor natural, solicitaron ayuda a todo aquel que se la pudiera proporcionar. De los pocos que acudieron a la llamada el más importante, sin duda, fue Ernesto Mansfeld, hijo ilegítimo del ya fallecido gobernador de los Países Bajos, Pedro Ernesto de Mansfeld y, por tanto, católico quien puso a disposición de los «directores» un contingente mercenario de 4.000 hombres. La mitad de estas tropas había sido levantada por Saboya para apoyar a Venecia contra Fernando de Estiria en la guerra uscoque, pero una vez acabado el conflicto se mantuvieron en activo pasando a servir a los estados bohemios ${ }^{10}$. Lo llamativo del caso es que la propaganda palatino-holandesa ocultó conscientemente este hecho, presentando este cuerpo de ejército como monolíticamente calvinista y alemán ${ }^{11}$. Y eso a pesar de que Carlos Manuel de Saboya mantuvo su apoyo a los rebeldes hasta que su general fue derrotado en la batalla de Zablatí, perdiendo en ella sus carros y bagaje con comprometedores papeles para Turín, por lo que tuvo que desdecirse de sus alianzas y abandonar discretamente a sus aliados ${ }^{12}$.

Pongamos otro ejemplo. El segundo. Y nos lo puede ofrecer la figura de Albrecht Wallenstein y su ejército ${ }^{13}$. Que al general bohemio la religión aparentaba importarle bien poco - desde luego menos que la astrología- es algo de sobra documentado en fuentes de época ${ }^{14}$. Nacido husita, criado como luterano y convertido al catolicismo, no parece que hubiera tenido inconveniente en servir a las órdenes del rey de Suecia si las condiciones lo hubieran permitido. Por ello, su ejército estuvo siempre plagado de soldados y oficiales de cualquier credo, algunos de los cuales como Jan de Weert o Johann von Götzen, a pesar de su filiación luterana, acabarán sirviendo a Baviera o incluso a la Monarquía Católica, cambiando de credo y convirtiéndose,

\footnotetext{
10. En relación con la guerra uscoque ver González Cuerva, 2014, en especial la nota 71.

11. Pursell, 2003, p. 49

12. Para Saboya en estos momentos, Osborne, 2002.

13. En este sentido Redlinch, 1964, ya afirmaba que el ejército de Wallenstein se vertebraba en torno a la fidelidad a su comandante por una cuestión de dinero y recompensas, no por credo y que, de hecho, este, al menos en sus niveles superiores, era una mezcolanza de oficiales protestantes y católicos. Asimismo documenta que no solo fue el ejército de Wallestein donde progresaron los protestantes como demuestra el caso de Melander que sirvió, sucesivamente, a los holandeses, venecianos, Hesse-Kasel y acabó sus días como comandante en jefe del ejército imperial, falleciendo frente a los franco-suecos en la batalla de Zusmarshausen (mayo de 1648) pp. 425-430. En Tercero Casado, 2015, p. 206 se recogen unas expresivas palabras del duque de Terranova respecto a este militar y su credo religioso.

14. La vida de Wallenstein se puede reconstruir a partir de Beladiez, 1967; Mann, 1978 y Mortimer, 2010.
} 
si era necesario, para lograr el medro personal y profesional ${ }^{15}$. Incluso el asesinato del Generalísimo fue una muestra de esa mixtura pues junto al irlandés Walter Butler participaron los escoceses Gordon y Leslie ${ }^{16}$. Si bien de este último no nos es dado afirmar su formación calvinista, sí que está documentado que había iniciado su periplo militar en las filas de las Provincias Unidas, de donde marchó a luchar con Dinamarca bajo cuyas banderas defendió Stralsund frente al duque de Friedland, constatándose que pasó a servir a Fernando II poco después y acabaría casando con una hija del conde Dietrichstein y formando parte de la nobleza imperial. De Gordon es innegable que, al menos hasta finales de los años treinta, continuó siendo presbiteriano a pesar de su buena relación con el mando vienés ${ }^{17}$. Luego, hablar de confesionalidad en el marco de los ejércitos es bastante inexacto y esta es una de las razones, la falta de identificación religiosa, que explican la facilidad con que unos contingentes pasaban de defender unas banderas a luchar por las contrarias. El dinero y la promesa de botín pesaban mucho más en el ánimo de los combatientes que la fe. Prosaico pero evidente a tenor a de las fuentes.

Pongamos ahora un tercer ejemplo muy diferente que centramos en analizar la coyuntura en el Sacro Imperio alrededor de 1629.

Por instigación de los jesuitas - con el confesor imperial a la cabeza-, la cancillería vienesa expide un documento terrible ya definido en la época como «la raíz de todos los males». Nos referimos, como es obvio, al Edicto de Restitución, un texto legal que iba más allá de ser un atentado confesional para convertirse también en un debelador del orden constitucional dentro del Imperio ${ }^{18}$. Es este el momento donde más claramente se puede hablar de «guerra de religión» pues el edicto afectaba tanto a calvinistas como luteranos. Pero ¿quién apoyó realmente este engendro? En realidad, solamente, Fernando $I^{19}$, parte de su corte y los deudos y aliados de Francia que veía en esta dinámica el hundimiento de la política de los Habsburgo en Alemania. Por eso, la Monarquía Hispánica con Olivares a la cabeza intentó, por todos los medios, impedirlo. De ahí que se presionase al Papa para que removiera al confesor imperial (sin ningún éxito) y se intentase in extremis un acercamiento a

15. Jean de Weert o Jan van Weert, militar nacido en Linburgo y, por tanto, vasallo de Felipe IV (cfr. Elliott y Negredo, en prensa, carta 22) sirvió en los ejércitos de la Liga -luchando en Nördlingen- y en el imperial, convirtiéndose al catolicismo para poder acceder a un título nobiliario bávaro. Findeisen, 1998, pp. 443-451. Johann von Götzen, conde de Götzen, inició su carrera al servicio del Elector Palatino como oficial en las unidades mercenarias de Ernesto de Mansfeld. Tras la derrota de este en el ataque a Dessau (1626) Götzen decidió cambiar de bando pasando a engrosar el ejército de Wallenstein con quien realizó la campaña del Báltico participando en el sitio de Stralsund. Tras la caída del Generalísimo siguió sirviendo a al emperador siendo el responsable de la pérdida de Breisach en 1638. Falleció combatiendo en la batalla de Jankovice (1645). Para su vida, ADB, 9, 510-511.

16. Mieck, 1996

17. De estos dos militares se ocupa con amplitud, Worthington, 2003 en diferentes páginas. Todavía en 1638 el padre John Seton se quejaba de que, a diferencia de sus parientes, «el coronel Gordon aún no es católico», p. 152, nota.

18. Se analiza el Edicto en Negredo, 2016, pp. 130-135, Wilson, 2009, pp. 446-454 o Bireley, 1981, pp. 74-84.

19. La concepción que el emperador tenía de las relaciones entre política y religión se explican en Brockmann, 2011. También pude consultarse Monod, 2001, pp. 113-122 
Sajonia para evitar lo que desde Madrid se adivinaba y temía y era que, si la política de implementación del edicto se llevaba a cabo, se entraría, entonces sí, en una guerra de religión -son palabras de don Gaspar de Guzmán- de impredecibles consecuencias. Pero precisamente esta última consideración es la que nos permite deducir que, con anterioridad, el conflicto no se consideraba desde aquella perspectiva ${ }^{20}$.

Porque, y esto es importante remarcarlo, desde 1618 hasta 1631 ni Sajonia ni Brandemburgo, electorados, como se sabe, protestantes, habían estado en guerra con el emperador, antes más, Juan Jorge, el monarca sajón, había colaborado eficazmente en el aplastamiento de la rebelión bohemia a cambio de recibir en pago las Lusacias ${ }^{21}$. Solo entre el otoño de 1631 y la primavera de 1635 estuvieron estos estados enfrentados con el kaiser siendo esos únicos cuatro años en los que podemos hablar con propiedad de bando católico y protestante.

Empero con todo, no se debe ignorar que Suecia, quien se presentó en Pomerania como liberadora de las libertades evangélicas y germánicas, cuando nadie le había llamado, tuvo que convencer por la fuerza - llegando a instalar sus cañones apuntando el palacio ducal en Berlín - a sus pretendidos aliados para que colaborasen con Gustavo Adolfo ${ }^{22}$. Pues bien esta Suecia estaba financiada liberalmente por Francia tras el tratado de Barwälde (23 de enero de 1631). Una Francia gobernada por su majestad cristianísima Luis XIII y dirigida con mano de hierro por el cardenal (de la iglesia católica) Richelieu que asimismo subvencionaba a las Provincias Unidas para que no cejaran en su guerra contra la Monarquía de Felipe IV y convencía a Tréveris para que abandonara el bando imperial permitiendo, un electorado católico, que las tropas suecas invernasen en sus tierras sin ser molestadas $^{23}$. De hecho, esta actitud profrancesa del elector arzobispal será entendida por Madrid como una provocación y un peligro -desde Tréveris se controlaban varios vados del Rin, se aislaba a Luxemburgo y se amenazaba el flanco sur de los Países Bajos leales - legitimando la acción armada que concluyó, ahí es nada, con la captura de todo un elector imperial y príncipe de la Iglesia. O dicho de otro modo, el monarca católico se convirtió en el carcelero de su eminencia Felipe Cristóbal

20. Con respecto a la posición de la Monarquía Hispánica frente al Edicto de Restitución, vertiente de la guerra ignorada o tergiversada por gran parte de la historiografía se puede consultar Negredo del Cerro y Villalba Pérez, 2015, en especial pp. 650-653. El intento de acercamiento a Sajonia en Negredo del Cerro, 2015

21. Juan Jorge ha sido uno de los dirigentes más criticados por la historiografía clásica de raíz germánica, precisamente por su papel pro-imperial en la contienda, destacando vicios que, siendo ciertos -es innegable su afición a la cerveza-compartía con otros contemporáneos (entre ellos Cristián IV o el general imperial Galasso) a los que se les recuerdan más benévolamente tales debilidades. Una visión más ponderada de su trayectoria en Gotthard, 2004. Su posición política ha sido estudiada asimismo por Gotthard, 1993.

22. Hay una buena síntesis de la discusión sobre las intenciones de Gustavo Adolfo a la hora de desembarcar en Alemania en un trabajo que, aunque antiguo, no ha perdido su vigencia, Ekman, 1966, pp. 251-252. Ver asimismo Roberts, 1957.

23. A este respecto resulta sumamente esclarecedor Esteban Estríngana, en prensa. 
de Sötern, ante las quejas de Francia y el papado, demostrando que las consideraciones geoestratégicas estaban muy por encima de los respetos confesionales ${ }^{24}$.

Un cuarto ejemplo de cómo la religión no explica casi nada de las raíces profundas de la guerra nos lo expone la propia Paz de Praga ${ }^{25}$. Por este acuerdo, sancionado tras la debacle sueca en Nördlingen - curiosa batalla obviada por gran parte de los manuales de historia militar nórdicos, franceses o anglosajones, entre otras cosas porque debela por sí misma otro de los muchos mitos de esta guerra como es la revolución militar y la supremacía de los ejércitos protestantes ${ }^{26}$ - lo que ha venido en denominarse protestantismo moderado, esto es, Sajonia, Brandemburgo y príncipes adheridos, decidieron no solo abandonar las armas sino pasar a engrosar con sus fuerzas los ejércitos imperiales. En mayo de 1635, por tanto, cinco de los siete electores originales se encontraban combatiendo en el mismo bando, y en el rival se mantenía un conde palatino, calvinista y refugiado en una corte anglicana y un elector católico, preso en Viena. Y a nivel global tan solo Brunswick y HesseKassel se mantenían eficazmente rebelados. Con esto datos, por tanto, se hace muy difícil hablar, desde ese año hasta 1648, de guerra de religión pues tan católica es Francia que lucha en un bando como protestante Sajonia que milita en el contrario pero aquella tiene como aliada a la Suecia luterana y esta a la Baviera papista ${ }^{27}$.

El quinto ejemplo que proponemos se centra en el reino de Dinamarca y sus dinámicas bélicas durante el conflicto de las cuales se desprende una curiosa paradoja.

Cuando Cristian IV decidió participar en los años veinte en el conflicto en calidad de jefe del círculo de la Baja Sajonia por sus títulos de duque de Holstein y Schleswig, lo hizo presentándose como defensor de la causa evangélica frente a la tiranía católica encarnada en los ejércitos de la Liga encabezados por Tilly. Sin embargo, y a pesar de las largas y continuadas negociaciones que habían precedido a esta decisión, a la hora de la verdad su entrada en el conflicto contó con muy pocos apoyos ya que la garantía de Mülhausen había desactivado gran parte de la oposición protestante al reconocer el emperador a los señores de aquel territorio la

24. Laufner, 1995. Agradezco a Alicia Esteban que me diese noticia de este artículo y a Manuel Pérez Cornejo su ayuda en la traducción de este y otros textos en alemán.

25. Insistimos en que el hecho de que la religión no explique las raíces profundas no implica que no sea básica para entender el conflicto. Tanto es así que muchos de sus contemporáneos lo vivieron como un asunto de lucha divina entre el demonio (el bando contrario) y la verdadera fe (la propia). Pero las lecturas subjetivas de los particulares inmersos en la coyuntura no deben confundirse con las causas subyacentes que condujeron a la guerra. Y entre merecen ser destacadas la lucha dinástica por la hegemonía, la pugna por el control de los espacios mercantiles más prósperos o el enfrentamiento político por el control de las instituciones locales y nacionales, entre otras.

26. Así, por ejemplo, en MacDonald, 2002 no se la menciona, pero se dedican cuatro páginas a Breitenfeld, y en Black, 2003, p. 68, apenas ocupa unas líneas frente al detenimiento con que se habla de la susodicha Breitenfeld, Lützen o Rocroi. Sobre el cuestionamiento de la revolución militar ver Parker, 1976 y la réplica de Parrott, 1995.

27. Bireley, 1976 estudia la negociación que llevó a la firma de este acuerdo con especial atención a la posición del confesor imperial, Lamormaini. El autor concluye que con la Paz de Praga se puso fin al mito de la Advocatio Ecclesiae, que había inspirado la política de Fernando Il y a partir de ese momento «the struggle in Germany lost much of its caracter as «holy war»» (p. 32). 
propiedad de los obispados y abadías secularizadas, desmontando la propaganda danesa. Además, sus maquinaciones para hacerse con la jefatura del círculo imperial, desplazando a su sobrino, Federico de Brusnwick, habían dejado al descubierto las verdaderas intenciones del soberano escandinavo que tenían mucho más que ver con apetencias geoestratégicas y económicas - dominio de los grandes estuarios con salida al mar del Norte y competencia con Suecia- que con la defensa de la fe. Que se apelase a esta, cuando sus fuerzas salieron en campaña, no hace sino reforzar la idea de que la religión era el mejor aglutinante de voluntades y la legitimación perfecta para encubrir decisiones que emanaban de otras dimensiones.

El caso es que a partir de este momento todos los estudios clásicos sobre la guerra nos hablan siempre de una fase danesa que se cercena tras la batalla de Lutter con la contundente derrota del rey Cristian antes los ejércitos combinados de Tilly y Wallenstein. Sin embargo, y he aquí la paradoja, estas mismas historias apenas dedican unas líneas a la segunda intervención danesa. La que se verifica entre 1643-164528.

El motivo de este silencio tiene una explicación clara, más allá de la nefasta conducción de la guerra y que esta fuese breve: parte de la base de que el conflicto se inició con un ataque sueco contra su vecino argumentando, como expuso el canciller Oxenstierna ante el Consejo de Estado, «sus maldades desde los tiempos de Lübeck», sin que en realidad mediase provocación alguna por parte de Cristian IV más allá de haber escoltado y albergado a la reina viuda María Eleonora de Brandemburgo, lance que la propaganda neerlandesa convirtió enseguida en una historia de amantes que atentaba contra la memoria de Gustavo Adolfo. Como tantas otras historias salidas de La Haya, nada de eso era verdad, pero como aquí no cabía apelar a la religión como causa justificativa -Copenhague y Estocolmo compartían credo luterano-, algo había que hacer. Y es que, en el fondo, la decisión sueca de atacar Dinamarca se basaba en las negociaciones que esta había llevado a cabo con la Monarquía Hispánica y que habían culminado en el tratado comercial de 20 de marzo de 1641, acompañado por un claro acercamiento hacia los círculos imperiales al postularse Cristian IV como posible intermediario entre los dos bandos. Todo ello, sumado a ciertas decisiones del monarca danés en relación a las cargas e impuestos que debían abonar las naves de los diferentes países al cruzar los estrechos del Sund, se conjugó para que las Provincias Unidas prometieran su apoyo a una Suecia que, una vez encarrilada su guerra en Alemania, sentía ahora amenazada su posición al norte de Germania. Y en este episodio se vuelve a constatar la nula operatividad de las categorías confesionales a la hora de explicar las causas de la guerra. Luteranos contra luteranos, apoyados estos por evangélicos y católicos, sustentados aquellos por calvinistas y papistas. ¿Dónde queda el horizonte confesional para delimitar bandos?

Y para terminar, pues no contamos con más espacio, entre las cuestiones que deben sopesarse a la luz de las nuevas interpretaciones no es la menor una lectura

28. Sobre Dinamarca en la Guerra de los Treinta años, Lockhart, 1996. Ver en este libro la desproporción entre el espacio dedicado a la intervención de los años veinte (varios capítulos) y las siete páginas donde se relata la guerra de 1643-1645 (pp. 259-265). 
más neutral de la propia paz de Westfalia, encumbrada por los herederos políticos e ideológicos de los vencedores hasta una categoría que podríamos denominar como de «madre de todos los tratados» cuando, si descendemos a su análisis pormenorizado, lo que en realidad hay es mucho de continuismo y muy poco de novedad más allá de la imposición de una serie de cláusulas a los derrotados a los que no se permitía, en algunos casos, ni siquiera personarse en los tratados ${ }^{29}$.

Pero centrándonos en los aspectos religiosos, que es lo que hoy nos interesa, lo primero que destacamos es la rapidez con que estos artículos se consensuaron. Nada raro si tenemos en cuenta que muchos de ellos no son sino un traslado de los pactados en la Paz de Praga cambiando la fecha de aplicación a 1624. En realidad Westfalia supuso la actualización de la confesión de Augsburgo ampliando a los calvinistas los derechos políticos de los luteranos pero ni mucho menos sancionó ningún tipo de libertad religiosa. Ni otros credos fueron admitidos ni se dejó de mantener el ordenamiento sancionado de «cuius regio, eius religio», de ahí que en los territorios patrimoniales de los Habsburgo se continuara manteniendo el catolicismo como única religión. Fernando III permitió que en el Imperio no primase la fe romana a cambio de que se le dejase las manos libres para implementarla allí donde reinara, lo cual, dicho sea de paso, sancionaba la derrota absoluta de los rebeldes bohemios.

O, con otras palabras, la fe se sometía a la necesidad política de imponer el absolutismo. Que el obispo de Salzburgo clamase en contra de estos acuerdos o que el Papa se negara a sancionarlos solo refuerzan la tesis de que los intentos por hacer del enfrentamiento confesional el vértice de la negociación habían fracasado; y habían fracasado, y esto creo que es importante remarcarlo, desde que las Provincias Unidas habían abandonado la lucha. Tras la paz de Münster de enero de 1648, uno de los principales responsables de mantener vivo el espíritu confesional en la lucha, había salido del conflicto. Y, con él, la voluntad de seguir ofreciendo cobertura religiosa a un enfrentamiento político. De ahí que, a pesar de las quejas y lamentos de los más intransigentes, tanto el corpus evangelicorum como el corpus catholicorum se pusieran de acuerdo sellando un modus vivendi que se perpetuará, no exento de tensiones en sus primeras fechas, durante los siguientes decenios. La cuestión confesional desaparecerá de las luchas intra-cristianos, dejándola solamente activa en el marco de las guerras contra la Sublime Puerta ${ }^{30}$.

29. La bibliografía sobre Westfalia es ingente. Para el lector español le pueden resultar de utilidad los trabajos reunidos en VV. AA., 1999, los que se publicaron en el número 19 de la revista Pedralbes o Masquardt, 2007. Una revisión crítica en Negredo del Cerro, 2016, pp. 337-343. Ver, también, Usunáriz, 2016, pp. 199-221.

30. No obstante, en los últimos años ha reverdecido una corriente historiográfica que postula la importancia de la religión como eje vertebrador de las relaciones internacionales al menos durante la segunda mitad del siglo XVII e, incluso, en el primer tercio del siglo XVIII. Para 1648 como año límite para las Ilamadas guerras de religión ver Thompson, 2009. En el caso específico hispano Storrs, 2009, delimita con precisión la diferencia entre ser un pilar ideológico y convertirse en el norte de actuación. También Martín Marcos, 2011, constata el fracaso de los intentos Clemente XI por reverdecer la influencia pontificia sobre la política europea al socaire de la Guerra de Sucesión. 
Una vez expuestos los hechos (que podríamos ampliar con bastantes más ejemplos) nos toca ahora reflexionar sobre ellos y, en especial, intentar explicar cómo es posible que hayan dado lugar a relatos tan sólidos y ampliamente aceptados. Y aquí la coyuntura política del siglo XIX, momento de creación de los grandes discursos historiográficos anclados, varios de ellos, en un nacionalismo militante $y$, como siempre, xenófobo, tiene mucho que decir.

Al presentar el problema en términos religiosos era muy sencillo caer en el terreno del maniqueísmo, que, de forma más o menos velada, tendía a identificar, moralmente hablando, a los «buenos» con el bando reformado y a los «malos» con los católicos que rodeaban al emperador encarnados en los «españoles ansiosos de guerra, frailes y jesuitas» ${ }^{31}$. Existiendo además una gradación entre los papistas pues no todos los católicos aparecían igual de perversos. Los vinculados a Francia -y entre ellos se contaba Baviera - tenían para esta historiografía un perfil tolerable mientras que todo aquel vinculado a la Casa de Habsburgo se identificaba con pensamiento retrógrado e intolerante. A nadie se le escapa que esta interpretación bebe directamente de una serie de fuentes diversas pero concomitantes: el nacionalismo alemán, germinado en torno a Prusia, que necesitaba del descrédito de la opción austriaca en el proceso de unificación; la prevalencia de la cosmovisión anglosajona en el momento de eclosión del imperialismo de la que será el máximo representante (no hace falta recordar los discursos de lord Salisbury); la debilidad del Imperio austro-húngaro frente a sus pujantes nacionalismo, entre ellos, para lo que nos interesa, el checo que retrotraía su legitimación a los sucesos de 1618 y, por último, la necesidad de Francia de reafirmarse en el tablero internacional tras su dura derrota en Sedán que impulsaba una idealización de los tratados de Westfalia toda vez que Alsacia y Lorena habían sido recuperadas por el mundo germánico.

Todos estos factores, unidos a otros de carácter muy diferente como la propia debilidad de la historiografía católica, en especial la española, a tono con el país, o la preocupación de la italiana por inventar un estado donde antes coexistían varios, se unieron a la hora de ofrecer una explicación «canónica« del conflicto que adoptó acríticamente la propaganda surgida al socaire de la guerra como una dimensión real del mismo dando lugar a un constructo que, como ha afirmado Schilling revistió de un halo de cientifismo positivista, los más burdas axiomas de la Leyenda $\mathrm{Negra}^{32}$. Y entre ellas el cifrar como norte de actuación de la Monarquía Hispánica la defensa a ultranza del catolicismo, lo que no era, ni por asomo, cierto ${ }^{33}$. Desconociendo absolutamente la documentación de esta institución, a la que se empecinaban en confundir con España, pues de esta forma soslayaban actores muy incómodos como el Franco Condado, el ducado de Milán o el País Bajo Obediente, se permitían una interpretación de la guerra que, fuerza es decirlo, rayaba en el simplismo y, desde luego, poco tenía que ver con lo que realmente había sucedido en el siglo $\mathrm{XV} \| I^{34}$.

31. Mann y Heuss, 1988, p. 239.

32. Schilling, 2002, p. 61.

33. Ver al respecto García Marín, 2017.

34. Ver las numerosos ejemplo que aporta Schmidt, 2012, libro muy esclarecedor al respecto. 
$Y$ en este horizonte -en donde conceptos como Contrarreforma se cargaron de tintes peyorativos aún en día rastreables ${ }^{35}$ - vino la guerra de los Treinta Años a inscribirse con inusitada precisión. Pero con todo, lo más llamativo es que, a pesar de los avances indudables de la historiografía a lo largo del siglo Xx, la idea de que esta contienda fue, sobre todo y a pesar de todo un conflicto confesional, no ha perdido fuerza. El desconocimiento que en otras latitudes sigue habiendo de toda las historiografía en torno a la Monarquía Hispánica, más allá de la aportación de los hispanistas, perdura ${ }^{36}$. Y con ello una lectura sesgada e interesada que no ha perdido todavía los resabios supremacistas que consideran impensable que la estrategia de la, por más que les pese, primera potencia europea del momento, fuera más allá de la defensa a ultranza de una fe inquisitorial. Solo negando esta posibilidad se consiguen mantener en pie la explicación confesional de la guerra. Hora es, creo, de que rescatemos otras posibles interpretaciones mucho más cercanas a la Europa del Barroco que las que hasta ahora nos han hecho llegar.

\section{BibliografíA}

Abreu y Bertodano, José, Colección de los tratados de paz, alianza, neutralidad, garantía [...] hechos por los pueblos reyes y príncipes de España con los pueblos, reyes, príncipes, repúblicas y demás potencias de Europa..., Parte V, Madrid, Juan de Zúñiga, Antonio Marín y la viuda de Peralta, 1745.

Beladiez, Emilio, España y el Sacro Imperio Romano Germánico. Wallenstein (15831634), Madrid, Prensa Española, 1967.

Bireley, Robert «The Peace of Prague (1635) and the Counterreformation in Germany», The Journal of Modern History, 48.1, 1976, pp. 31-70.

Bireley, Robert, Religion and Politics in the Age of the Counterreformation. Emperor Ferdinand, William Lamormaini (S.I.) and the Formation of Imperial Policy, Chapel Hill, University of North Carolina Press, 1981.

Black, Jeremy, La guerra. Del Renacimiento a la Revolución, 1492-1792, Madrid, Akal, 2003.

35. Tanto es así que hoy en día ha dejado de ser empleado por gran parte de la historiografía. No es este el lugar para plantear un debate historiográfico al respecto pero, en nuestra modesta opinión, el constructo puede ser válido si se le despoja de la carga de negatividad aportada por sus acuñadores y no creemos que pueda ser sustituido - aunque sí complementado- por otras narrativas que se centren en la reforma o renovación católica. Claro que una discusión en profundidad al respecto habría de llevarnos más lejos y cuestionarnos si la propia idea de confesionalización, tan aceptada en la actualidad, no presenta perfiles tan netamente diferenciados entre el mundo católico y el protestante que quizá su operatividad deba ser limitada.

36. Como muestra, un botón. Estando ultimando estas líneas ha llegado a mis manos la edición en castellano del primer volumen de la obra de Wilson sobre la Guerra de los Treinta Años. En sus páginas finales recoge una bibliografía de más de setecientos títulos de las que solo dos están en castellano (y sospechamos que uno de ellos introducido por el propio editor español). Creo que con un dato así, sobran los comentarios. 
Brockmann, Thomas, «Religion und Politik bei Ferdinand II», en La dinastía de los Austria. Las relaciones entre la Monarquía Católica y el Imperio, coord. José Martínez Millán y Rubén González Cuerva, Madrid, Polifemo, 2011, vol. I, pp. 125-135.

Chaline, Olivier, La bataille de la Montagne Blanche. Un mystique chez les guerriers, París, Noesis, 1999.

Ekman, Ernst, «Three Decades of Research on Gustavus Adolphus», The Journal of Modern History, 38.3, September 1966, pp. 243-255.

Esteban Estríngana, Alicia, «Entre deslealtad dinástica y trama antiespañola: la conjura nobiliaria flamenca de 1632 a la luz del tratado franco-holandés de 1635», en Paradigmes rebelles. Pratiques et cultures de la désobéissance à l'époque moderne, ed. Gregorio Salinero, Águeda García Garrido y Paun Radu, Genève, Peter Lang, en prensa.

Findeisen, Jörg-Peter, Der Dreissigjährige Krieg: eine Epoche in Lebensbildern, Graz/Viena/Colonia, Styria Premium, 1998.

Forclaz, Bertrand, y Martin, Philippe (dirs.), Religion et piété au défi de la guerre de Trente Ans, Rennes, Presses Universitaires de Rennes, 2015.

García Marín, José María, «Razón de Estado y razón de Dios en la práctica política de la Monarquía española (1511-1664)», Cuadernos de Historia del Derecho, 24, 2017, pp. 11-34.

González Cuerva, Rubén, «Italia y la Casa de Austria en los prolegómenos de la Guerra de los Treinta Años», en Centros de poder italianos en la Monarquía Hispánica (siglos XV-XVIII), coord. José Martínez Millán y Manuel Rivero Rodríguez, Madrid, Polifemo, 2014, vol. I, pp. 415-480.

Gotthard, Axel, «"Politice seint wir Bäpstisch". Kursachsen und der deutsche Protestantismus im frühen 17. Jahrhundert», Zeitschrift für Historische Forschung, 20, 1993, pp. 275-319.

Gotthard, Axel, «Johann Georg I. 1611-1656», en Die Herrscher Sachsens, ed. FrankLothard Kroll, Munich, C. H. Beck Verlag, 2004, pp. 137-147.

Greengrass, Mark, La destrucción de la Cristiandad. Europa, 1517-1648, Barcelona, Pasado y Presente, 2015.

Laufner, Richard, «Die Gefangennahme des Trierer erzbischofs und kurfürsten Philipp Christoph von Sötern», en Kreis Trier-Saarburg: Ein Jahrbuch zur Information Belehrung und Unterhaltung, 1985, pp. 176-180.

Lockhart, Paul Douglas, Denmark in the Thirty Years War, 1618-1648: King Christian IV and the Decline of the Oldenburg State, Pennsilvania, Susquehanna University Press, 1996. 
Lutz, Heinrich, Reforma y Contrarreforma. Europa entre 1520 y 1648, Madrid, Alianza, 2009 [1. . ed. 1982].

MacDonald, John, Grandes batallas de la Historia. Decisiones estratégicas de las Guerras Púnicas a la Guerra de Secesión, Barcelona, Ediciones Folio, 2002.

Mann, Golo, Wallenstein, Barcelona, Grijalbo, 1978.

Mann, Golo, y Heuss, Alfred (dirs.), De la Reforma a la Revolución, Madrid, Espasa Calpe, 1988.

Martín Marcos, David, El Papado y la Guerra de Sucesión española, Madrid, Marcial Pons, 2011.

Masquardt, Bernd, «El mito del sistema de Westfalia: una re-evaluación de la cesura de 1648 en la historia del derecho internacional público», en Pensamiento jurídico, 20, 2007, pp. 103-134.

Mieck, Ilja, «L'assassinat de Wallenstein (1634)», en Complots et conjurations dans L'Europe Moderne, ed. Yves-Marie Bercé y Elena Fasano, Roma, École Française de Rome, 1996, pp. 507-534.

Monod, Paul K., El poder de los reyes. Monarquía y religión en Europa, 1589-1715, Madrid, Alianza, 2001.

Mortimer, Geoff, Wallenstein: The Enigma of the Thirty Years War, Nueva York, Palgrave, 2010.

Negredo del Cerro, Fernando, «Un episodio español en la Guerra de los Treinta Años: la embajada del marqués de Cadreita al Sacro Imperio y el acercamiento al Elector Sajón (1629-1631)», Hispania, LXXV, 251, 2015, pp. 669-694.

Negredo del Cerro, Fernando, La Guerra de los Treinta Años. Una visión desde la Monarquía Hispánica, Madrid, Síntesis, 2016.

Negredo del Cerro, Fernando, y Villalba Pérez, Enrique, «Los jesuitas y la Monarquía Hispánica en el contexto de la Guerra de los Treinta Años (1625-1635)», Hispania Sacra, 136, 2015, pp. 635-672.

Osborne, Toby, Dynasty and Diplomacy in the Court of Savoy. Political Culture and the Thirty Years' War, Cambridge, Cambridge University Press, 2002.

Palomo, Federico, «Confesionalización», en Identidades y fronteras culturales en el mundo ibérico de la Edad Moderna, ed. José Luis Betrán y Bernat Hernández, Doris Moreno, Barcelona, UAB, 2016, pp. 69-89.

Parker, Geoffrey, «The "Military Revolution" 1560-1660. A Myth?» Journal of Modern History, 48, 1976, pp. 195-214.

Parrott, David A., «Strategy and Tactics in the Thirty Years' War. The "Military Revolution"», en The Military Revolution Debate, ed. Clifford J. Rogers, Oxford, Westview, 1995, pp. 227-251. 
Polisensky, Josef V., The Thirty Years War, Londres, New English Library, 1974.

Pursell, Brenan C., The Winter King. Frederick V of the Palatinate and the Coming of the Thirty Years' War, Aldershot/Burlington, Ashgate, 2003.

Repgen, Konrad, «What is a Religious War?», en Politics and Society in Reformation Europe, ed. E. I. Kouri y Tom Scott, Londres, Macmillan Press, 1987, pp. 311-328.

Ringmar, Erik, Identity, Interest and Action: A Cultural Explanation of Sweden's Intervention in the Thirty Years War, Cambridge, Cambridge University Press, 1996.

Roberts, Michael, "The Political Objectives of Gustavus Adolphus in Germany, 1630-1632», Transactions of the Royal Historical Society, 5. ${ }^{a}$ serie, núm. 7, 1957, pp. 19-46.

Rystad, Göran, Kriegnachrichten und Propaganda während des Dreißigjährigen Krieges, Lund, Gleerup, 1960.

Schilling, Heinz, «Del Imperio común a la leyenda negra. La imagen de España en la Alemania del siglo XVI y comienzos del XVII», en España y Alemania. Percepciones mutuas de cinco siglos de historia, ed. Henning Wegener y Miguel Ángel Vega Cernuda, Madrid, Editorial Complutense, 2002, pp. 37-62.

Schmidt, Peer, La monarquía universal española y América. La imagen del imperio español en la Guerra de los Treinta Años (1618-1648), México, FCE, 2012.

Sonnino, Paul, «From d'Avaux to dévot: Politics and Religion in the Thirty Years War», History, 87, 2002, 192-203.

Steinberg, S. Henry, The "Thirty Years' War» and the Conflict for European Hegemony, 1600-1660, Nueva York, Norton Co., 1966.

Storrs, Christopher, «The Role of Religion in Spanish Foreign Policy in the Reign of Carlos II (1665-1700)», en War and Religion after Westphalia, 1648-1713, ed. David Onnekink, Surrey, Routledge, 2009, pp. 25-46.

Tercero Casado, Luis, «¿Pax non sancta? La postura de la diplomacia española ante la política religiosa del emperador Fernando III en la Paz de Westfalia», en Antemurales de la fe. Conflictividad confesional en la Monarquía de los Habsburgo, 1516-1714, ed. Pedro García Martín, Roberto Quirós Rosado y Cristina Bravo Lozano, Madrid, UAM/Ministerio de Defensa, 2015, pp. 197-212.

Thompson, Andrew C., «After Westphalia: Remodelling a Religious Foreing Policy», en War and Religion after Westphalia, 1648-1713, ed. David Onnekink, Surrey, Routledge, 2009, pp. 47-68.

Usunáriz, Jesús M., España en Alemania: la Guerra de los Treinta Años en crónicas y relaciones de sucesos, Nueva York, IDEA, 2016.

VV. AA., 350 años de la Paz de Westfalia, 1648-1998. Del antagonismo a la integración en Europa, Madrid, Fundación Carlos de Amberes/Biblioteca Nacional de España, 1999. 
Wedgwood, Cicely Veronica, The Thirty Years War, Londres, Methuen, $1981\left[1 .{ }^{a}\right.$ ed. 1938].

Wilson, Peter H., Europe's Tragedy. A History of the Thirty Years War, Londres, Penguin Books, 2009

Worthington, David, Scots in the Habsburg Service, 1618-1648, en History of Warfare, vol. 21, Leiden, Brill, 2003. 